\title{
Analysis of spudcan-footprint interaction in a single soil with nonlinear FEM
}

\author{
Dong-Feng Mao $\cdot$ Ming-Hui Zhang $\cdot$ \\ Yang Yu $\cdot$ Meng-Lan Duan $\cdot$ Jun Zhao
}

Received: 27 January 2014/Published online: 24 January 2015

(C) The Author(s) 2015. This article is published with open access at Springerlink.com

\begin{abstract}
The footprints that remain on the seabed after offshore jack-up platforms completed operations and moved out provide a significant risk for any future jack-up installation at that site. Detrimental horizontal and/or rotational loads will be induced on the base cone of the jack-up platform leg (spudcan) in the preloading process where only vertical loads are normally expected. However, there are no specific guidelines on design of spudcan re-installation very close to or partially overlapping existing footprints. This paper presents a rational design approach for assessing spudcan-footprint interaction and the failure process of foundation in a single layer based on nonlinear finite element method. The relationship between the distance between the spudcan and the footprint and the horizontal sliding force has been obtained. Comparisons of simulation and experimental results show that the model in this paper can deal well with the combined problems of sliding friction contact, fluid-solid coupling, and convergence difficulty. The analytical results may be useful to jack-up installation workovers close to existing footprints.
\end{abstract}

Keywords Jack-up · Existing footprint - Spudcanfootprint interaction $\cdot$ Numerical simulation $\cdot$ Nonlinearity

\section{Introduction}

With an increase in frequency of operations, the situation that installation of jack-up platforms on sites which contains old

D.-F. Mao $(\varangle) \cdot$ M.-H. Zhang · Y. Yu · M.-L. Duan · J. Zhao College of Mechanical and Transportation Engineering, China University of Petroleum, Beijing 102249, China

e-mail: maodf@cup.edu.cn

Edited by Yan-Hua Sun footprints is becoming more common and inevitable. According to van den Berg's statistics (Van den Berg et al. 2004), within Shell EP Europe alone roughly 1,200 footprint points had been registered in geotechnical and footprint datasets. In addition, there are approximately 80 new single footprint points added to the existing datasets every year. Thus, it can be seen that footprints are not rare and they pose a serious and growing threat to operational safety of jack-up drilling platforms. Figure 1 shows when a leg is close to an existing footprint, the non-uniform bearing load caused by the footprint will make the spudcan slide into the footprint in the jacking process, which was proven by Gaudin et al. (2007), Leung et al. (2007). The sliding trend is affected by the leg stiffness, connection between leg and hull, and inplace condition of other two legs, and the size of the trend is measured by the horizontal sliding force and overturning moment (McClelland et al. 1982; Hossain and Randolph 2007; Bouwmeester et al. 2009). If a slide occurs, the legs will incline in different directions, so that the legs may become stuck in the platform and this would mean the platform cannot be raised. The potential risk of slipping is a serious threat to the operational safety of platforms.

Re-installing a spudcan very close to or partially overlapping existing footprints is generally not recommended in the guidelines (SNAME OC-7 panel. 2007; Hossain and Randolph 2008). In a situation where this is inevitable, the guidelines recommend the use of an identical jack-up (same footing geometries and leg spacing) and locating it in exactly the same position as the previous unit, where possible. However, it is unlikely that two jack-up units have an identical design because the structures of most units are often custom-made and the deployments of units are subject to availability. It is evident that existing guidelines are not adequate for rig operators to install jackup units in close proximity to existing footprints safely. 
Fig. 1 Schematic diagram of existing footprint problems

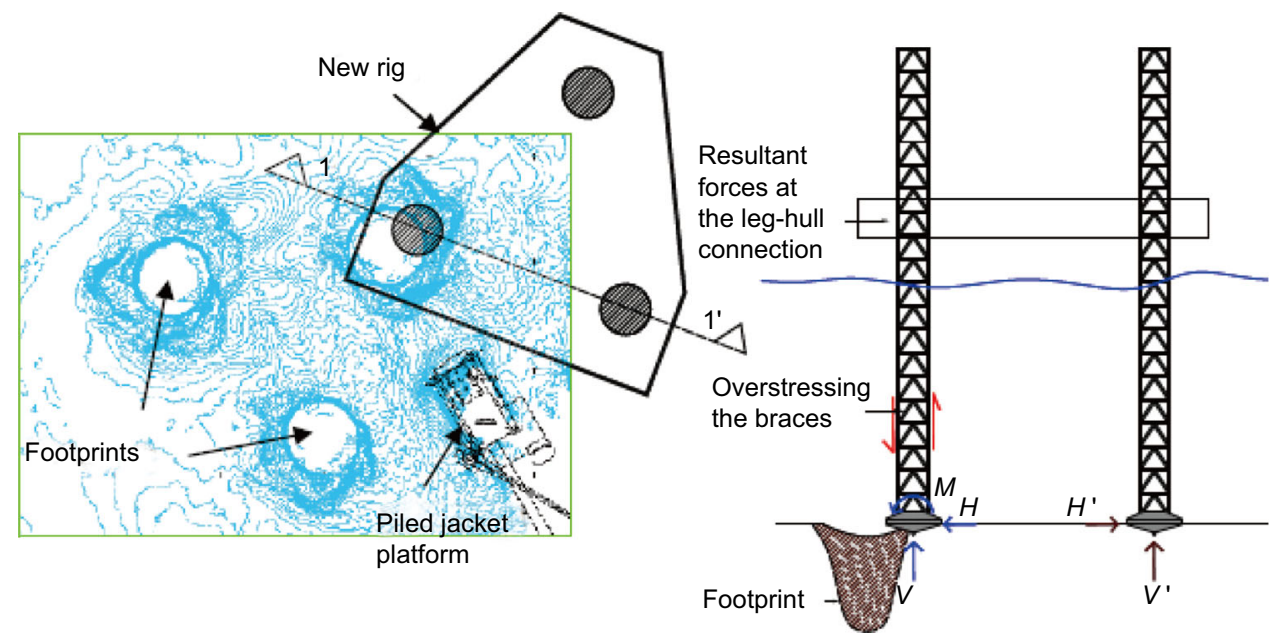

Footprint issues involve soil elastoplasticity, material and geometric nonlinearities, fluid-solid coupling, friction contact during spudcan preloading, and difficult convergence of numerical solutions (Hanna and Meyerhof 1980; Kellezi and Stromann 2003; DeJong et al. 2004; Deng and Kong 2005; Leung et al. 2008). Previous research mainly focuses on the spudcan-footprint interaction through the centrifuge model test. Murff et al. (1991), Hossain et al. (2005), Cassidy et al. (2004, 2009), Teh et al. (2010), Gan (2009), Gan et al. (2012), Kong et al. (2010, 2013), Xie et al. (2012) conducted a series of drum centrifuge model tests to investigate spudcan-footprint interaction and the effect of leg stiffness on spudcan-footprint interaction. With the centrifuge model tests, Stewart and his coworkers (Stewart 2005; Stewart and Finnie 2001) studied the effect of bending rigidity of legs on spudcan-footprint interaction and the influence of the distance between the spudcan and the footprint on sliding. Dean and Serra (2004) discussed the effect of equivalent stiffness of legs on spudcan-footprint interaction. Teh et al. (2006) reported a set of test results investigating the effects of sloping seabed $\left(30^{\circ}\right.$ inclined to the horizontal) and footprint on loads developed in jack-up legs. They found that the effect of the footprint is much greater than that of the seabed slope. This indicates that the footprint problem is more serious than a sloping seabed. Other researchers have tried to investigate the footprint problem with numerical simulation (Zhang et al. 2011, 2014). Jardine et al. (2002) simplified a threedimensional model to a plane strain one to deal with footprint issues. The current understanding of this topic is still insufficient, and only a small number of studies of the footprint problem are available in the public domain. Although it is a great challenge to obtain a converged numerical solution, a good numerical model and solution is very important because it is able to achieve more accurate estimation of carrying capacity of spudcans and better explanations for tests. This paper takes various factors including failure process of foundation, nonlinearity, sliding friction contact, and fluid-solid coupling into account. It discusses the finite element model of spudcan-footprint interaction in spudcan re-installation near an existing footprint as well as handling relative parameters. With the model of the spudcan-footprint interaction, the changes of horizontal sliding force on the spudcan at different offset distances between the spudcan and the footprint were analyzed with ABAQUS software. The finite element model was validated by comparing the simulation result with experimental results.

\section{Analytical methods and computing model}

During jacking, the deformation of the surrounding soil is very large, which results in changes in pore pressure and then a reduction in the effective strength of the soil. To analyze spudcan-footprint interaction, the coupling of stress/fluid flow in soil should be considered. Undrained total stress analysis is used in the computing model, i.e., the total stress is the sum of effective stress and hydrostatic pressure. Thus, the equilibrium equation in the vertical direction is as follows (Houlsby and Martin 2003):

$\frac{\mathrm{d} \bar{\sigma}_{\mathrm{z}}}{\mathrm{d} z}=\left\{\begin{array}{l}\rho g-\gamma_{\mathrm{w}}\left(S_{\mathrm{r}}\left(1-n^{0}\right)-\frac{\mathrm{d} S_{\mathrm{r}}}{\mathrm{d} z}\left(z_{\mathrm{w}}^{0}-z\right)\right) ; \quad z \leq z_{\mathrm{w}}^{0}, \\ \rho g ; \quad z_{\mathrm{w}}^{0} \leq z \leq z^{0}\end{array}\right.$

where $\bar{\sigma}_{z}$ is the vertical stress, $\mathrm{Pa} ; \rho$ is the soil dry density, $\mathrm{kg} / \mathrm{m}^{3} ; \gamma_{\mathrm{w}}$ is the water gravity density, $\mathrm{N} / \mathrm{m}^{3} ; S_{\mathrm{r}}$ is the soil saturation, $\% ; z_{\mathrm{w}}^{0}$ is the free water surface elevation, $\mathrm{m} ; z^{0}$ is the elevation of interface between dry soil and partially saturated soil, $\mathrm{m}$; and $n^{0}$ is porosity, \%; when $z \leq z_{\mathrm{w}}^{0}$ in 
completely saturated, $S_{\mathrm{r}}=1$, and when $z_{\mathrm{w}}^{0} \leq z \leq z^{0}$, in partially saturated, $S_{\mathrm{r}}<1$.

The advantage of ABAQUS in soil engineering is that it provides not only various elastic/plastic constitutive models for soil but also coupled analysis of stress/fluid flow in soil. In numerical computation, the finite element mesh is fixed on the soil skeleton, and fluid may flow through the mesh and satisfy the fluid continuity equation. The Forchheimer equation (Zeng and Grigg 2006) is adopted to describe nonlinear flow in soil (porous medium). Since less relative parameters in calculation are needed, the MohrCoulomb constitutive model is used (Li 2004), i.e., the soil is considered as a perfect elastic-plastic material, and obeys the noncorrelation flow rule. The Mohr-Coulomb yield criterion is as follows:

$s+\sigma_{\mathrm{m}} \sin \phi-c \cos \phi=0$,

where $s=\left(\sigma_{1}-\sigma_{3}\right) / 2$ is half of the difference of maximum and minimum principal stresses, $\mathrm{kPa} ; \sigma_{\mathrm{m}}=\left(\sigma_{1}+\right.$ $\left.\sigma_{3}\right) / 2$ is the average value of maximum and minimum principal stresses, $\mathrm{kPa} ; c$ is cohesion, $\mathrm{kPa}$; and $\phi$ is the internal friction angle, ${ }^{\circ}$. Except for over-consolidated soil, clay always shows little dilatancy, and thus the dilatancy angle $\phi=0$. Assume that the deformation modulus is approximately proportional to the undrained shear strength, then $E=500 s_{\mathrm{u}}\left(s_{\mathrm{u}}\right.$ is the undrained shear strength, $\left.\mathrm{kPa}\right)$.

A vertical plane containing the line connecting the spudcan and the footprint center is chosen and a finite element model is established, as shown in Fig. 2. The diameter and depth of the footprint are $D$ and $d$, respectively. In order to reduce the boundary effect on accuracy of the numerical simulation, the width and depth of the surrounding soil are taken as $15 D$ and $7 d$, respectively. The offset distance between the spudcan and the footprint center is denoted as $S$. The 8-node plane strain and pore pressure element, CPE8PR, is used to simulate the soil element to avoid self-locking phenomena and to increase the computational accuracy in numerical simulation. The active-passive surface contact algorithm is used to deal with the contact interaction and relative displacement

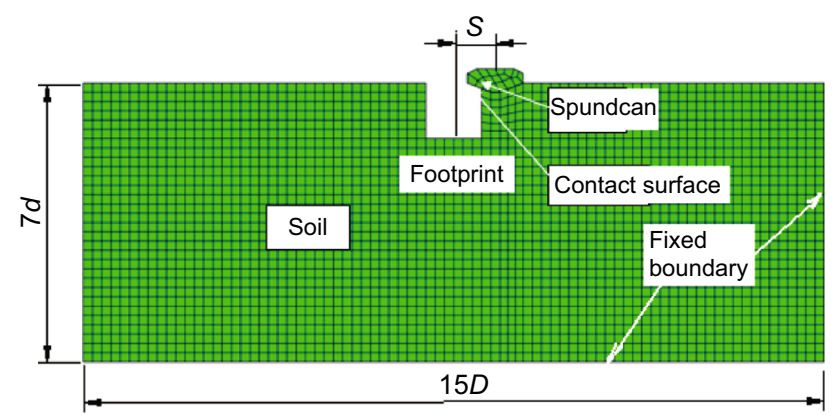

Fig. 2 Schematic diagram of the finite element model between the spudcan and the surrounding soil, and the spudcan surface is taken as the active surface and the soil surface as the passive surface (Zhuang et al. 2005). The principle for choosing an active or passive surface is that the mesh of the passive surface should be finer, and if both mesh densities are similar to each other, the surface of the softer material should be passive. The tangential contact obeys the Coulomb friction law, and the normal contact follows the hard touching mode, i.e., penetration is not allowed between the spudcan element and the soil element, but they are allowed to separate (Zhuang et al. 2005). In order to obtain the correct horizontal sliding force-displacement curve, the displacement control method is used to load. A simplified spudcan, with its side friction ignored because of its relative smaller area, is adopted to reduce the difficulty of convergence in calculation. The friction coefficients for undrained clay and drained granular soil are $0.2-0.3$ and $\tan \delta$, respectively, where $\delta$ is the friction angle between the spudcan and the soil. It must be pointed out that whether setting a reasonable degree of spudcansoil contact will lead to the calculation converging or not.

Since the ultimate bearing capacity would be underestimated if the initial geo-stress equilibrium were not considered in numerical simulation, this paper deals with the initial geo-stress equilibrium first and imports a stress file with an 'initial conditions' method. This is instead of the 'Geostatic' way, a commonly used geo-stress equilibrium analysis method in general simulation involving in soil that is difficult to deal with for such a complex problem as spudcan-soil interaction with an existing footprint. In addition, because of serious soil deformation under a large spudcan penetration depth, in order to avoid huge warping and ensure accuracy of calculation, ALE self-adaptive meshes are employed.

\section{Spudcan-footprint interaction in clay}

\subsection{Failure process of clay foundations}

Let $S=0.75 D(D=6 \mathrm{~m}, d=6 \mathrm{~m})$. The mechanical characteristics of uniform soil such as clay are shown in Table 1.

The gradual failure process of clay foundation occurs in three stages: elastic balance, plastic expansion, and complete plastic damage (Fig. 3). Figure 3a shows that plastic damage first appears at the bottom edge of the footprint

Table 1 Material parameters of single-layer foundation

\begin{tabular}{lll}
\hline $\begin{array}{l}\text { Effective density } \\
\rho, \mathrm{kg} / \mathrm{m}^{3}\end{array}$ & $\begin{array}{l}\text { Cohesion } \\
C, \mathrm{kPa}\end{array}$ & $\begin{array}{l}\text { Internal friction } \\
\text { angle } \phi,{ }^{\circ}\end{array}$ \\
\hline 860 & 20 & 0 \\
\hline
\end{tabular}


close to the spudcan. Figure $3 \mathrm{~b}$ shows the expansion of the soil foundation plastic zone from the bottom edge of the footprint toward the farther edge of the spudcan with load increasing. Figure $3 \mathrm{c}$ indicates that when the complete plastic damage of clay foundation appears, the plastic zones have expanded to form a continuous sliding surface.

\subsection{Clay foundation yield at different $S$}

Changing only $S$ while keeping other parameters constant, the situations of clay foundation yield at different $S$ are

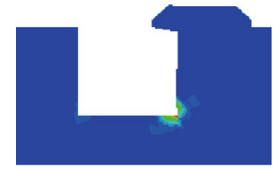

(a)

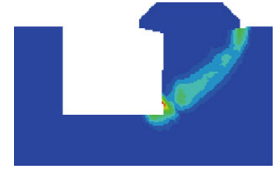

(b)

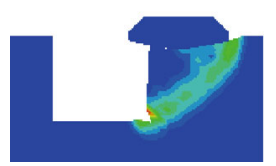

(c)
Fig. 3 Plastic zone of clay foundation in loading (part around the footprint) shown in Fig. 4. This indicates that the plastic zone becomes larger with an increase in $S$ and the failure pattern of soil around the spudcan gradually changes from asymmetric to symmetric.

\subsection{Soil movement patterns at different $S$}

When the spudcan arrives at the designed depth, the soil displacement vectors under different $S$ are shown in Fig. 5, from which we see that there is an obvious uplift trend at the bottom of the footprint and the soil near the footprint clearly migrates toward the footprint. The bulge on the farther side surface of the clay foundation changes little with an increase in $S$. However, the apophysis on the footprint bottom increases significantly and the soil movement patterns on the closer side to the spudcan and below the spudcan change greatly. When $S$ is small, part of the soil below the spudcan moves to the footprint, while another part migrates downward with the spudcan. With the $S$ increasing, the soil under the spudcan bottom

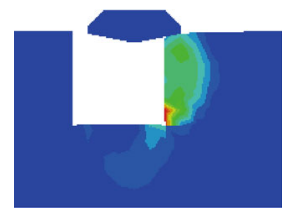

(a) $S=1$

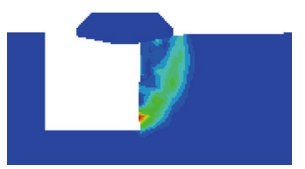

(b) $S=2$

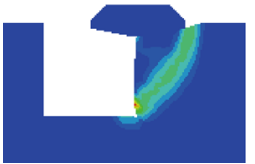

(c) $S=3$

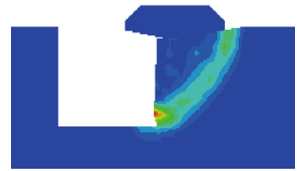

(d) $S=4$

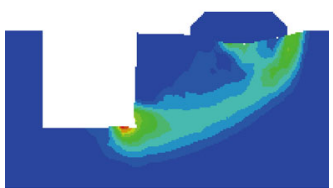

(i) $S=9$

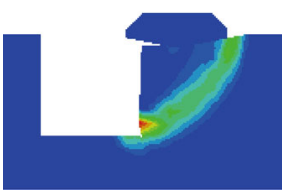

(e) $S=5$

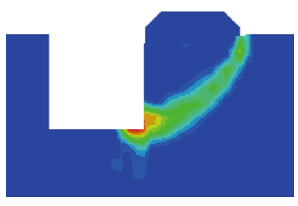

(f) $S=6$

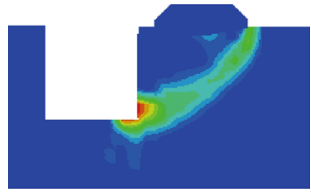

(g) $S=7$

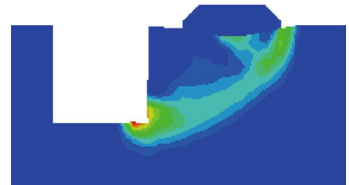

(h) $S=8$

Fig. 4 The complete plastic damage zone at different $S$ (part around the footprint)

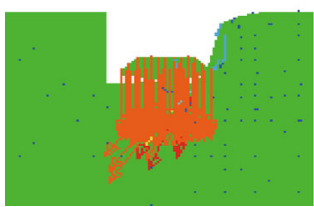

(a) $S=1$

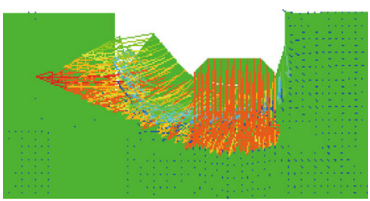

(f) $S=6$

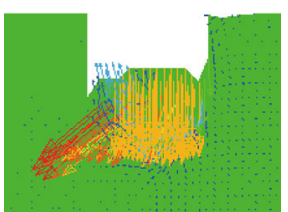

(b) $S=2$

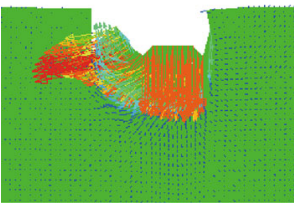

(g) $S=7$

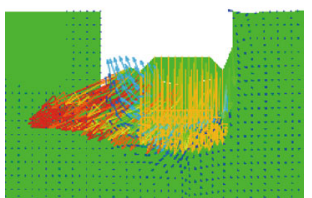

(c) $S=3$

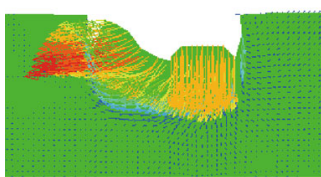

(h) $S=8$

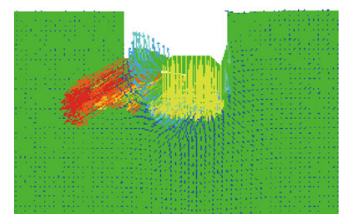

(d) $S=4$

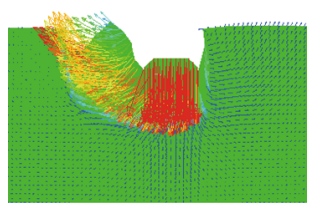

(i) $S=9$

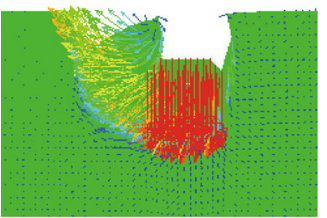

(e) $S=5$

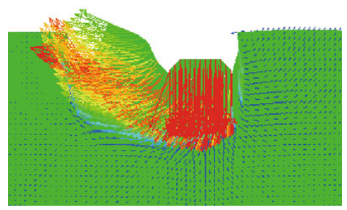

(j) $S=10$

Fig. 5 The displacement vector of clay at different $S$ (part around the spudcan) 
basically migrates downward, while most of the soil on the closer side of the footprint moves into the footprint and only a little moves downward with the spudcan edge. This may provide a coping idea for jack-up re-installation close to footprint (which will be discussed in a separate paper).

\subsection{Influence of $S$ on horizontal slip force}

The relation between the horizontal slipping force on the spudcan and the spudcan vertical displacement, i.e., depth at different $S$ is displayed in Fig. 6. This shows that at any $S$, with the depth increasing, the horizontal force on the spudcan increases initially then decreases after it reaches a peak value. The peak values at different $S$ appear at a depth from 2.5 to $4.5 \mathrm{~m}$, and the maximum peak horizontal force is about $0.7 \mathrm{MN}$ when $S=4 \mathrm{~m}$. This indicates that the most potentially dangerous situation is when the spudcan partially overlaps the existing footprint. In order to investigate the overall relationship between the peak horizontal force on the spudcan and $S$, the peak horizontal forces are sorted at different $S$ in dimensionless form (Table 2).

For the problem with a 'footprint,' the horizontal slip force on the spudcan varies with soil strength, footprint dimension, diameter of the spudcan, and the offset distance between the spudcan and the footprint center. Taking these factors into consideration, the expression of the peak horizontal force on the spudcan in dimensionless form can be summarized as

$H_{\max }=f^{\prime}\left(\frac{D_{\mathrm{s}}}{D_{\mathrm{f}}}, \frac{S}{D_{\mathrm{f}}}, \frac{d}{D_{\mathrm{f}}}\right) \times s_{\mathrm{u}} D_{\mathrm{s}}^{2}$,

where $H_{\max }$ is the peak horizontal force on the spudcan, $\mathrm{MN} ; S_{\mathrm{u}}$ is the soil undrained shear strength; $D_{\mathrm{f}}$ is the diameter of the footprint, $\mathrm{m} ; D_{\mathrm{s}}$ is the diameter of the

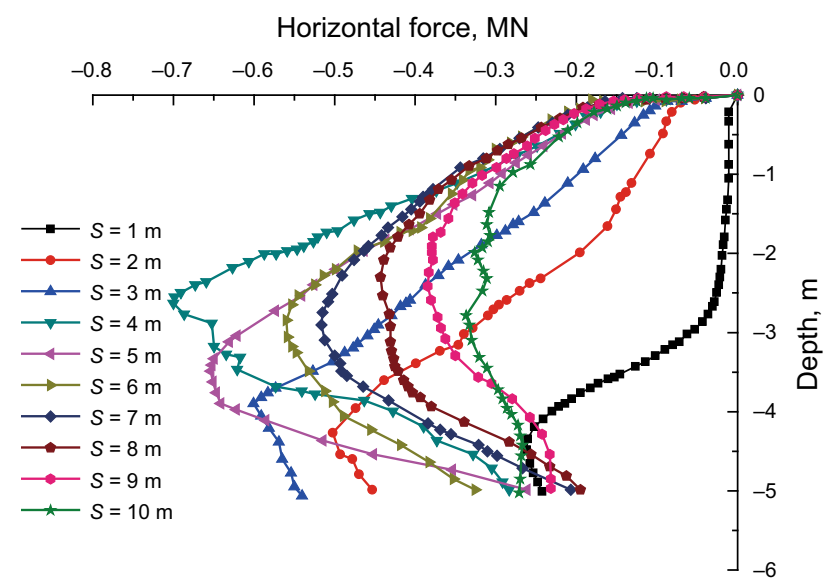

Fig. 6 The horizontal force-depth diagram at different $S$
Table 2 Peak horizontal forces at different ' $S$ '

\begin{tabular}{lll}
\hline$S, \mathrm{~m}$ & $S / D$ & Peak horizontal force, MN \\
\hline 1 & 0.166 & 0.264 \\
2 & 0.333 & 0.497 \\
3 & 0.498 & 0.593 \\
4 & 0.664 & 0.698 \\
5 & 0.834 & 0.653 \\
6 & 1.000 & 0.561 \\
7 & 1.166 & 0.504 \\
8 & 1.333 & 0.443 \\
9 & 1.498 & 0.383 \\
10 & 1.664 & 0.326 \\
\hline
\end{tabular}

spudcan in future operations, $\mathrm{m} ; S$ is the distance between the spudcan and the footprint center, $\mathrm{m}$; and $d$ is the depth of the footprint, $\mathrm{m}$.

In this paper, only the influence of the offset distance on the peak horizontal slip force on the spudcan is considered, as given in Table 2. The horizontal force on the spudcan will be zero when $S=0$ as the spudcan is located exactly in the footprint. Using Matlab to fit the numerical simulation results, the peak horizontal force on the spudcan is obtained as follows:

$H_{\max }=4.1248 \cdot\left(\frac{S}{D_{\mathrm{f}}}\right)^{1.3439} \times \exp \left(-1.9555 \frac{S}{D_{\mathrm{f}}}\right)$,

The fitting curve of Eq. (4) and the numerical simulation results are shown in Fig. 7. This demonstrates that the curvature tolerance of Eq. (4) is very small and it could reliably represent the relationship between the peak horizontal sliding force on the spudcan and the offset distance $S$. The peak horizontal force reaches a maximum value

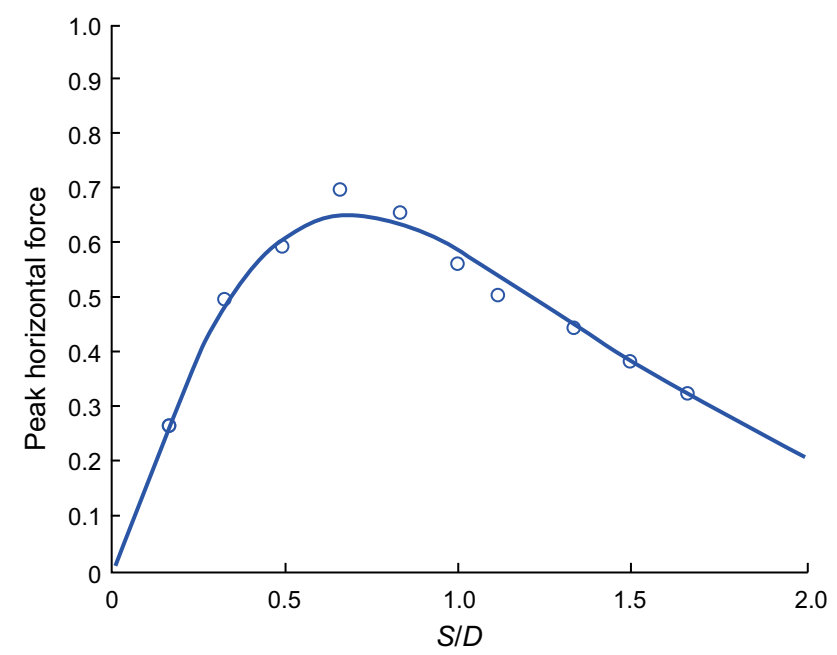

Fig. 7 The fitted curve between the peak horizontal force and $S$ 


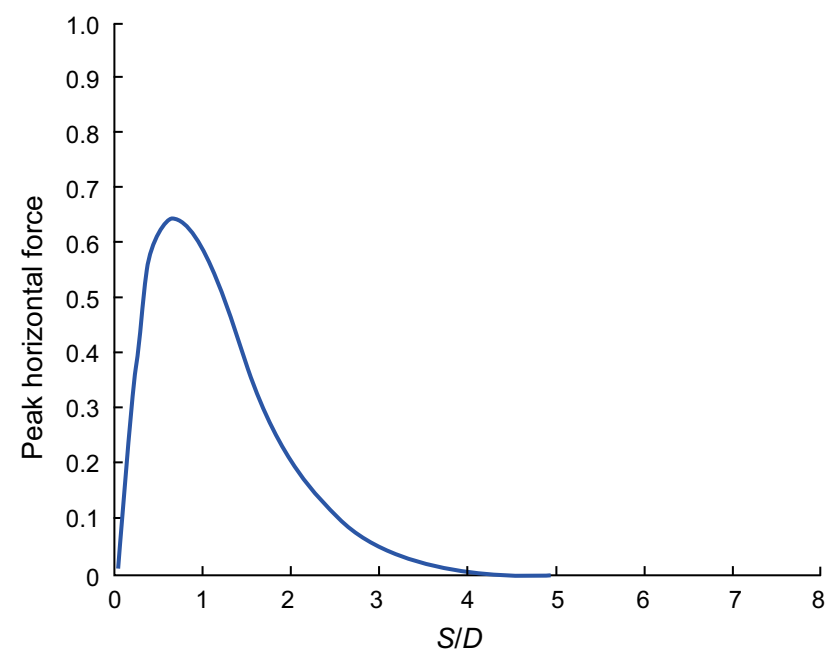

Fig. 8 The whole relation between the peak horizontal force and $S$

when $S / D=0.6$. The horizontal force increases quickly before it reaches the maximum value and then gradually decreases. The rate of decrease is far less than the rate of increase. In order to observe the successive change of the peak horizontal force, the horizontal force is calculated at larger ' $S$ according to Eq. (4), and the whole relation between the peak horizontal sliding force and the offset distance is given in Fig. 8. When $S / D \geq 5$, the peak horizontal force becomes almost zero, which means in this case that the influence of the existing footprint could be ignored.

\section{Verification of numerical simulation results}

Based on the University of Western Australia centrifuge model test (Table 3; Gan 2009), we built 2-dimensional and 3-dimensional simulation models (Fig. 9) to conduct finite element simulation. Results at different $S(0.25 D$, $0.50 D, 0.75 D, 1.0 D)$ are shown in Figs. 10 and 11. Comparisons of results from the 2-dimensional or 3-dimensional simulation models and from the experiments indicate that the simulation results are in good agreement with experimental results, and the results from the 3-dimensional model are a little closer to the test results than those from the 2-dimensional model. However, with the 3-dimensional model, not only the computing time needed is much longer, but also the calculation is much more difficult to converge. Using the 2-dimensional model built in this paper would significantly reduce the necessary computing time, and the simulation results are in good agreement with experimental results, which shows that the 2-dimensional model built in this paper is feasible and reliable.

Table 3 List of major experimental parameters (after Gan 2009)

\begin{tabular}{|c|c|c|c|c|c|c|c|c|c|c|c|c|}
\hline \multirow[t]{3}{*}{ Test No. } & \multicolumn{4}{|c|}{ Spudcan diameter } & \multicolumn{5}{|c|}{ Initial penetration } & \multicolumn{2}{|c|}{ Re-penetration } & \multirow[t]{3}{*}{ Remarks } \\
\hline & \multirow{2}{*}{$\begin{array}{l}\text { Initial } \\
\text { penetration } \\
D_{\mathrm{f}}, \mathrm{m}\end{array}$} & \multirow{2}{*}{\multicolumn{2}{|c|}{$\begin{array}{l}\text { Re-penetration } \\
D_{\mathrm{s}}, \mathrm{m}\end{array}$}} & \multirow{2}{*}{$\begin{array}{l}\text { Size } \\
\text { ratio } \\
D_{\mathrm{f}} / D_{\mathrm{s}}\end{array}$} & \multicolumn{3}{|c|}{ Soil strength profile } & \multirow{2}{*}{$\begin{array}{l}\text { Preload } \\
\text { pressure } \\
q_{0}, \mathrm{kPa}\end{array}$} & \multirow{2}{*}{$\begin{array}{l}\text { Penetration } \\
\text { depth } \\
d_{0}, \mathrm{~m}\end{array}$} & \multirow{2}{*}{$\begin{array}{l}\text { Radial } \\
\text { distance } \\
R_{\mathrm{d}}, \mathrm{m}\end{array}$} & \multirow[t]{2}{*}{$R_{\mathrm{d}} / D_{\mathrm{f}}$} & \\
\hline & & & & & $s_{\mathrm{um}}, \mathrm{kPa}$ & $k, \mathrm{kPa} / \mathrm{m}$ & $k D_{\mathrm{f}} / s_{\mathrm{um}}$ & & & & & \\
\hline OA1 & 6 & 6 & & 1 & 25 & 5 & 1.20 & 460 & 5.84 & 0.0 & 0.00 & Tests done \\
\hline $\mathrm{OA} 2$ & 6 & 6 & & 1 & 28 & 5 & 1.07 & 460 & 5.61 & 1.5 & 0.25 & in NUS \\
\hline OA3 & 6 & 6 & & 1 & 28 & 5 & 1.07 & 460 & 5.30 & 3.0 & 0.50 & \\
\hline $\mathrm{OA} 4$ & 6 & 6 & & 1 & 28 & 5 & 1.07 & 460 & 5.19 & 4.5 & 0.75 & \\
\hline OA5 & 6 & 6 & & 1 & 28 & 5 & 1.07 & 460 & 5.19 & 6.0 & 1.00 & \\
\hline OA6 & 6 & 6 & & 1 & 30 & 5 & 1.00 & 460 & 4.70 & 9.0 & 1.50 & \\
\hline \multirow[t]{3}{*}{ Test No. } & \multirow{3}{*}{$\begin{array}{l}\text { Size } \\
\text { ratio } D_{\mathrm{f}} / D_{\mathrm{s}}\end{array}$} & \multirow[t]{3}{*}{$R_{\mathrm{d}} / D_{\mathrm{f}}$} & \multirow{3}{*}{\multicolumn{2}{|c|}{$\begin{array}{l}\text { Depth ratio } \\
d_{\mathrm{s}} / D_{\mathrm{f}}\end{array}$}} & \multicolumn{8}{|c|}{ Re-penetration } \\
\hline & & & & & \multicolumn{4}{|c|}{ Maximum horizontal load, $H_{\max }$} & \multicolumn{4}{|c|}{ Maximum moment, $M_{\max }$} \\
\hline & & & & & $d / D_{\mathrm{s}}$ & $H_{\max }, \mathrm{MN}$ & $\theta$, degree & $H / s_{\mathrm{u}} D_{\mathrm{s}}^{2}$ & $d / D_{\mathrm{s}}$ & $M_{\max }, \mathrm{MN}$ & $e / D_{\mathrm{s}}$ & $M / s_{\mathrm{u}} D_{\mathrm{s}}^{3}$ \\
\hline OA1 & 1 & 0.00 & 0.97 & & 1.02 & 0.11 & 0.54 & 0.06 & 0.98 & 0.31 & 0.005 & 0.03 \\
\hline $\mathrm{OA} 2$ & 1 & 0.25 & 0.94 & & 0.75 & 0.41 & 2.76 & 0.20 & 0.78 & 1.81 & 0.033 & 0.14 \\
\hline OA3 & 1 & 0.50 & 0.88 & & 0.84 & 0.49 & 2.32 & 0.23 & 0.44 & 1.91 & 0.047 & 0.15 \\
\hline OA4 & 1 & 0.75 & 0.87 & & 0.52 & 0.72 & 4.29 & 0.34 & 0.10 & 2.29 & 0.109 & 0.18 \\
\hline OA5 & 1 & 1.00 & 0.86 & & 0.78 & 0.63 & 2.69 & 0.30 & 0.27 & 2.13 & 0.047 & 0.17 \\
\hline OA6 & 1 & 1.50 & 0.78 & & 0.88 & 0.30 & 1.15 & 0.14 & 0.44 & 0.45 & 0.007 & 0.03 \\
\hline
\end{tabular}




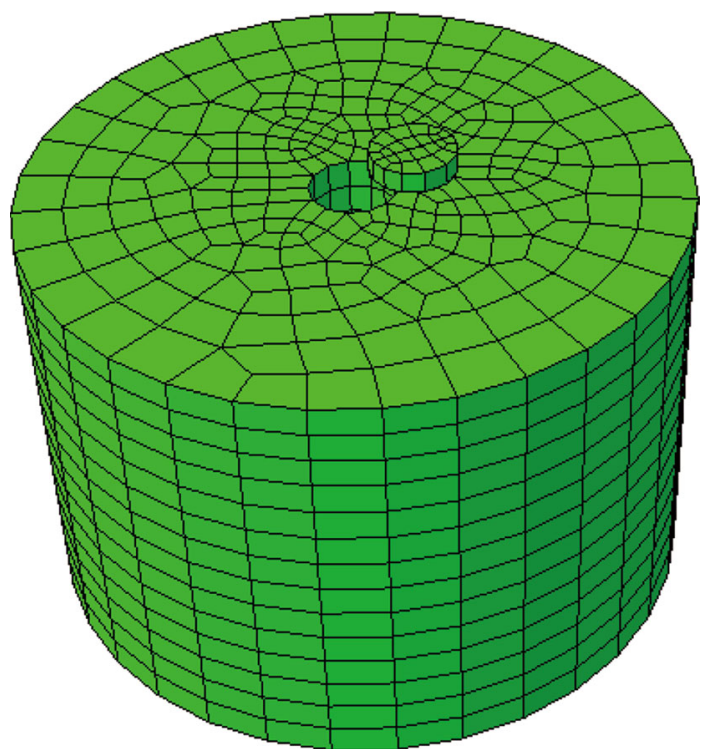

Fig. 9 3-dimensional finite element model

\section{Conclusions}

1. In the initial loading stage, plastic damage first appears at the bottom edge of the footprint close to the spudcan. Then the plastic zone expands with increasing load and finally it forms a continuous sliding surface.

2. With an increase in the distance between the spudcan and the footprint, the soil failure pattern gradually changes from asymmetric to symmetric.

3. The soil migration patterns on the closer side of the footprint and below the spudcan change greatly at different offset distances. With the distance increasing, the soil on the spudcan bottom basically migrates downward, while most of the soil on the closer side of the footprint moves into the footprint, and only a little moves downward with the spudcan edge. This means "stomping" (repeated raising and lowering of the jackup leg) may be a successful solution for the jack-up installation close to a footprint.

4. The peak horizontal sliding forces on spudcan at different offset distances modeled with Matlab to fit the numerical simulation results and the possible dangerous ranges during re-installation have been obtained. The peak horizontal force reaches its maximum value when $S / D=0.6$. When $S / D \geq 5$, the horizontal sliding force becomes almost zero, which means in this case that the influence of the footprint could be ignored.

5. The numerical simulation results show good agreement with experimental results, indicating clearly that the finite element model built in this paper can be used to solve the problems of spudcan-footprint interaction with sliding friction contact, fluid-solid coupling, nonlinear elastic-plastic deformation, and convergence problems.

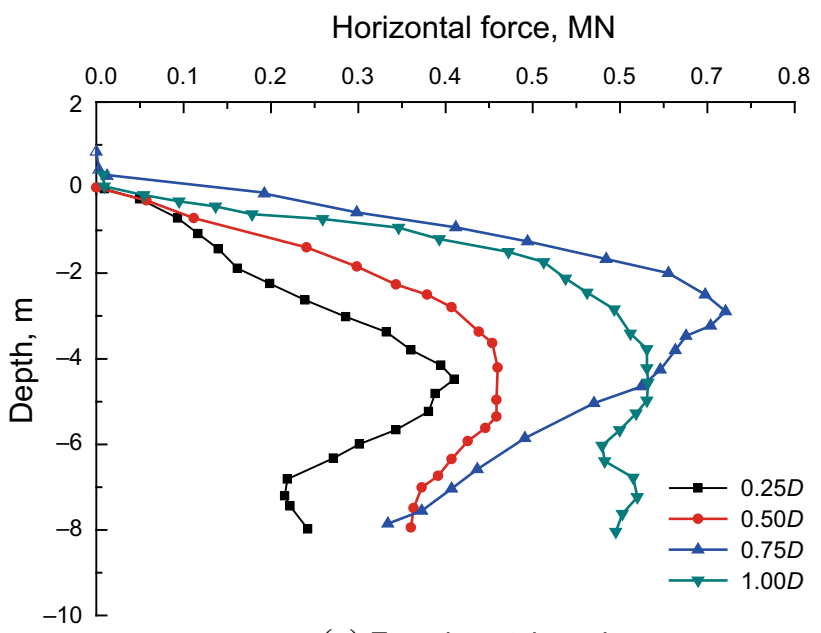

(a) Experimental results

Horizontal force, $\mathrm{MN}$

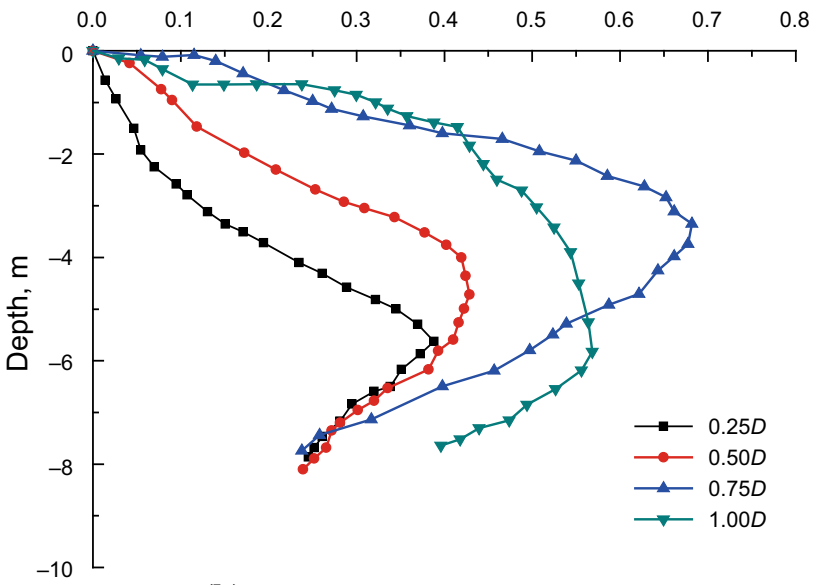

(b) 2-dimensional simulation results

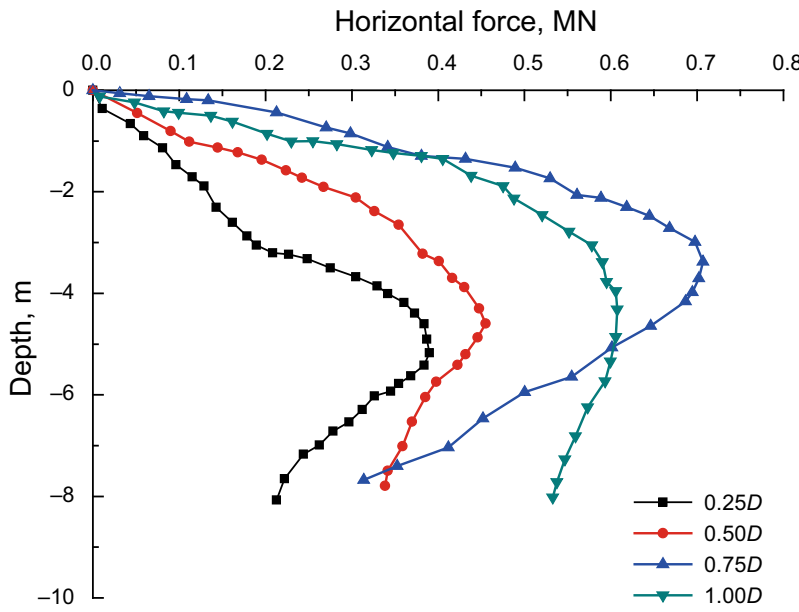

(c) 3-dimensional simulation results

Fig. 10 Simulation and experimental results 

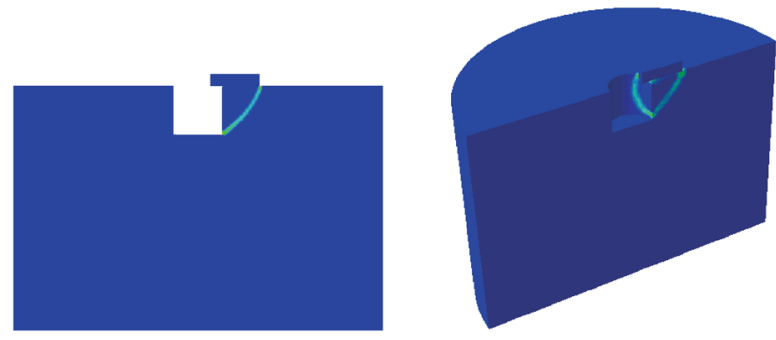

(a) The plastic zone in the loading of clay foundation

Fig. 11 2-dimensional and 3-dimensional numerical simulation results

Acknowledgments This work is financially supported by the National Natural Science Foundation of China (Grant No. 51379214) and the National Science and Technology Major Project (Grant No. 2011ZX05027-005-001).

Open Access This article is distributed under the terms of the Creative Commons Attribution License which permits any use, distribution, and reproduction in any medium, provided the original author(s) and the source are credited.

\section{References}

Bouwmeester D, Peuchen J, Van der Wal T, et al. Prediction of breakout forces for deepwater seafloor objects. In: Offshore technology conference, OTC-19925-MS. Houston; 4-7 May 2009.

Cassidy MJ, Byrne BW, Randolph MF. A comparison of the combined load behaviour of spudcan and caisson foundations on soft normally consolidated clay. Géotechnique. 2004;54(2):91-106.

Cassidy MJ, Quah CK, Foo KS. Experimental investigation of the reinstallation of spudcan footings close to existing footprints. J Geotech Geoenviron Eng (ASCE). 2009;135(4):474-86.

Dean ER, Serra H. Concepts for mitigation of spudcan-footprint interaction in normally consolidated clay. In: Proceedings of the 14th international offshore and polar engineering conference. (ISOPE ISOPE-I-04-248), Toulon; 23-28 May 2004.

DeJong JT, Yafrate NJ, DeGroot DJ, Jakubowski J. Evaluation of the undrained shear strength profile in soft layered clay using fullflow probes. In: Proceedings of the 2 nd international conference on site characterisation. Porto; 2004. pp. 679-86.

Deng CJ, Kong WX. Analysis of ultimate bearing capacity of foundations by elastoplastic FEM through step loading. Rock Soil Mech. 2005;26(3):500-4 (in Chinese).

Gan CT. Centrifuge model study on spudcan-footprint interaction doctoral dissertation. Perth: The University of Western Australia; 2009.

Gan CT, Leung CF, Cassidy MJ, Gaudin C, Chow YK. Effect of time on spudcan-footprint interaction in clay. Géotechnique. 2012;62(5):402-13.

Gaudin C, Cassidy MJ, Donovan T. Spudcan reinstallation near existing footprints. In: Proceedings of the 6th international offshore site investigation and geotechnics conference: confronting new challenges and sharing knowledge. London: Society of Underwater Technology; 2007. pp. 285-92.

Hanna AM, Meyerhof G. Design chart for ultimate bearing capacity of foundation on sand overlying soft clay. Can Geotech J. 1980;17(2):300-3.

Hossain MS, Hu Y, Randolph MF, White DJ. Limiting cavity depth for spudcan foundations penetrating clay. J Geotech. 2005;55(9): 679-90.
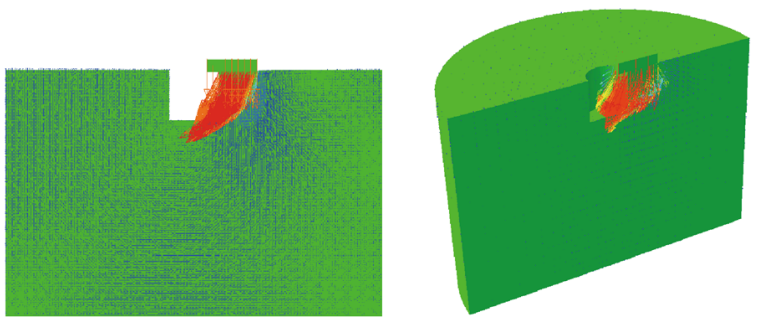

(b) The displacement vector of clay foundation

Hossain MS, Randolph MF. Investigating potential for punch-through for spud foundations on layered clays. In: Proceedings of the 17th ISOPE. Lisbon; 1-6 July 2007. pp. 1510-17.

Hossain MS, Randolph MF. Overview of spudcan performance on clays: current research and SNAME. In: Proceedings of the 2nd jack-up Asia conference \& exhibition. Singapore; 2008.

Houlsby GT, Martin CM. Undrained bearing capacity factors for conical footings on clay. Géotechnique. 2003;53(5):513-20.

Jardine RJ, Kovacevic N, Hoyle MJR, Sidhu HK, Letty A. Assessing the effects on jack-up structures of eccentric installation over infilled craters. In: Society for underwater technology (SUT), proceedings of international conference. Offshore site investigation and geotechnics-diversity and sustainability, London; 26-28 Nov 2002. pp. 307-24.

Kellezi L, Stromann H. FEM analysis of jack-up spud penetration for multi-layered critical soil conditions. Lyngby: GEO-Danish Geotechnical Institute; 2003. pp. 411-20.

Kong VW, Cassidy MJ and Gaudin C. (2010) Jack-up reinstallation near a footprint cavity. In: Proceedings of the 7th international conference on physical modelling in geotechnics, (ICPMG). Zurich; 28 Jun-1 Jul 2010. pp. 1033-38.

Kong VW, Cassidy MJ, Gan CT. Experimental study of the effect of geometry on the reinstallation of a jack-up next to a footprint. Can Geotech J. 2013;50(5):557-73.

Leung CF, Gan CT, Chow YK. Shear strength changes within jack-up spudcan footprint. In: Proceedings of the 17th international offshore and polar engineering conference, ISOPE-I-07-485. Lisbon; 1-6 Jul 2007.

Leung CF, Xie Y, Chow YK. (2008) Use of PIV to investigate spudcanpile interaction. In: Proceedings of the international offshore and polar engineering conference. Vancouver; 2008. p. 721.

Li G. Advanced Soil Mech. Beijing: Tsinghua University Press Ltd; 2004.

McClelland B, Young A, Remmes BD. Avoiding jack-up rig foundation failure. Geotech Eng. 1982;13(2):151-88.

Murff JD, Himilton JM, Dean ETR, James RG, Kusakabe O, Schofield AN. Centrifuge testing of foundation behaviour using full jack-up rig models. In: Proceedings of 32nd offshore technology conference, OTC 6516. Houston; 1991.

SNAME recommended practice for site specific assessment of mobile jack-up units. Technical secretary to SNAME OC-7 panel. 2007.

Stewart DP, Finnie IMS. Spudcan-footprint interaction during jack-up workovers. In: Proceedings of the 11st of international offshore and polar engineering conference, (ISOPE-I-01-011). Stavanger; 17-22 Jun 2001.

Stewart DP. Influence of jack-up operation adjacent to a piled structure. Frontiers in offshore geotechnics: ISFOG. Perth; 2005. pp. 516-23.

Teh KL, Byrne BW, Houlsby GT. Effects of seabed irregularities on loads developed in legs of jack-up units. In: Jack up Asia conference and exhibition, Singapore; 2006. 
Teh KL, Leung CF, Chow YK, Chow MJ. Centrifuge model study of spudcan penetration in sand overlying clay. Géotechnique. 2010;60(11):825-42.

Van den Berg B, Hulshof B, Tijssen T, van Oosterom P. Harmonisation of distributed geographic datasets: a model driven approach for geotechnical \& footprint data. Delft: Delft University of Technology; 2004.

Xie Y, Leung CF, Chow YK. Centrifuge model study of spudcan-pile interaction. Géotechnique. 2012;62(9):799-810.

Zeng Z, Grigg R. A criterion for non-darcy flow in porous media. Transp Porous Media. 2006;63(1):57-69.
Zhang Y, Bienen B, Cassidy MJ, Gourvenec S. The undrained bearing capacity of a spudcan foundation under combined loading in soft clay. Mar Struct. 2011;24(4):459-77.

Zhang Y, Wang D, Cassidy MJ, Bienen B. Effect of installation on the bearing capacity of a spudcan under combined loading in soft clay. J Geotech Geoenviron Eng, ASCE. 2014. doi:10.1061 GT. 1943-5606.0001126.

Zhuang Z, Zhang F, Cen S. ABAQUS nonlinear finite element analysis and samples. Beijing: Science Press; 2005 (in Chinese). 